\title{
SI gene sequence analysis of a nephropathogenic strain of avian infectious bronchitis virus in Egypt
} Ahmed S Abdel-Moneim*1, Magdy F El-Kady², Brian S Ladman³ and
Jack Gelb Jr ${ }^{3}$

Address: ${ }^{1}$ Department of Virology, Faculty of Veterinary Medicine, Beni-Suef University, Beni-Suef 62511, Egypt, ${ }^{2}$ Department of Poultry Diseases, Faculty of Veterinary Medicine, Beni-Suef University, Beni-Suef 62511, Egypt and ${ }^{3}$ Department of Animal and Food Sciences, University of Delaware, Newark, DE 19717, USA

Email: Ahmed S Abdel-Moneim* - a_s_abdel_moneim@yahoo.com; Magdy F El-Kady - mfelkady@yahoo.com; Brian S Ladman - bladman@udel.edu; Jack Gelb - jgelb@udel.edu

* Corresponding author

Published: 20 September 2006

Virology Journal 2006, 3:78 doi:10.1 186/1743-422X-3-78

This article is available from: http://www.virologyj.com/content/3/I/78

(c) 2006 Abdel-Moneim et al; licensee BioMed Central Ltd.

This is an Open Access article distributed under the terms of the Creative Commons Attribution License (http://creativecommons.org/licenses/by/2.0), which permits unrestricted use, distribution, and reproduction in any medium, provided the original work is properly cited.

\begin{abstract}
Background: Infectious bronchitis is highly contagious and constitutes one of the most common and difficult poultry diseases to control. IBV is endemic in probably all countries that raise chickens. It exists as dozens of serotypes/genotypes. Only a few amino acid differences in the SI protein of vaccine and challenge strains of IBV may result in poor protection. Tropism of IBV includes the respiratory tract tissues, proventriculus and caecal tonsils of the alimentary tract, the oviduct and the kidney.
\end{abstract}

Results: Infectious bronchitis virus (IBV) strain closely related to Massachusetts (Mass) serotype was isolated from broiler chickens suffering from severe renal and respiratory distresses. The isolate was serologically identified by Dot-ELISA and further characterized by RT-PCR then genotyped using SI gene sequence analysis. Alignment of the SI sequence of the isolate with I6 IBV strains revealed high homology to isolates related to Mass serotype. Inoculation with the strain reproduced the disease in experimental I-day-old chickens and resulted in $20 \%$ mortality, severe renal and moderate respiratory distresses. Marked histopathological changes in both kidney and trachea were observed in experimentally infected chickens. A protection study using the $\mathrm{H} / 20$ live attenuated vaccine showed low protection rate in spite of high SI sequence homology (97\%). Protection based criteria were: virus re-isolation attempts from trachea, tracheal and renal histopathology as well as IBV antigens detection by immunofluorescent antibody technique in kidney sections.

Conclusion: Periodical evaluation of cross-protective capabilities of IBV vaccine(s) versus recently recovered field isolates should be performed to ensure optimum control of IBV.

\section{Background}

Avian infectious bronchitis virus (IBV) is a highly contagious pathogen of chickens that replicates primarily in the respiratory tract and also in some epithelial cells of the gut, kidney and oviduct [1]. IBV is a virus member of genus Coronavirus, family Coronaviridae, order Nidovirales [2]. The virus possesses a positive stranded RNA genome that encodes phosphorylated nucleocapsid pro- 
tein $(\mathrm{N})$, membrane glycoprotein $(\mathrm{M})$, spike glycoprotein (S) and small membrane protein (E). The spike glycoprotein is post-translationally cleaved into two subunits, S1 and S2 [1,3]. The S1 protein forms the N-terminal portion of the peplomer and contains antigenic epitopes mainly within three HVRs [4-6]. Neutralizing and serotype specific epitopes are associated within the defined HVRs $[4,7,8]$.

Variation in S1 sequences [9-11], has been recently used for distinguishing between different IBV serotypes. Diversity in S1 probably results from mutation, recombination and strong positive selection in vivo [12]. Antigenically different serotypes and newly emerged variants from field chicken flocks sometimes cause vaccine breaks. The generation of genetic variants is thought to be resulted from few amino acid changes in the spike (S) glycoprotein of IBV $[13,14]$.

In Egypt, isolates related to Massachusetts, D3128, D274, D-08880, 4/91 and the novel genotype; Egypt/Beni-Suef/ 01 were isolated from different poultry farms [15-18]. The commonly used IBV attenuated vaccine is $\mathrm{H} 120$ while the Mass 41 (M41) strain is commonly used in inactivated vaccines.

In the present study, Egypt/F/03 was isolated from 25day-old broiler chickens in Fayoum Governorate, identified by Dot-ELISA, RT-PCR and sequenced to determine its serotype. Pathogenicity test to 1-day-old chickens and protection afforded by the commonly used H120 live attenuated vaccine were also performed.

\section{Results}

Virus isolation and serological identification

The allantoic fluid of the first chicken embryo passage of Egypt/F/03 was harvested at 48 h PI. Four additional egg passages were performed. Five eggs of the $4^{\text {th }}$ passage were incubated till being 18-day-old and all of them (100\%) showed typical lesions of the IBV (stunting and dwarfing). The virus identity was ascertained by performing DotELISA on the CAM homogenate (Fig. 1).

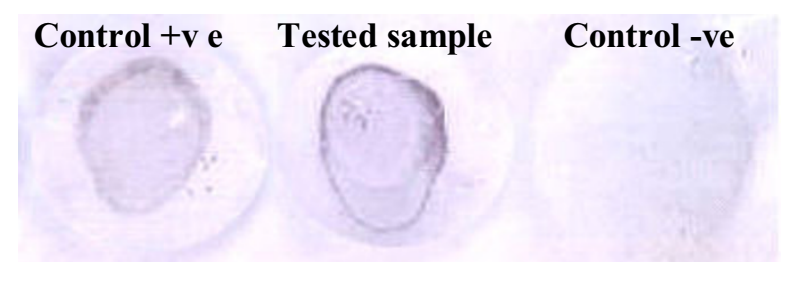

\section{Figure I}

Dot-ELISA shows positive reaction in tested (chorioallantoic membrane homogenate) and control positive sample.

\section{Polymerase chain reaction and SI gene cycle sequencing} RT-PCR of Egypt/F/03 resulted in a product of 1600 base pairs using S1 primers OLIGO 5' and OLIGO 3'. Egypt/F/ 03 is closely related to the Beaudette US reference strain; $98 \%$ nucleotide identity and 96\% amino acid identity (Table 1 and Fig. 2). It showed 97\% similarities both in nucleotides and amino acids to $\mathrm{H} 120$ and 98\% nucleotide and $96 \%$ amino acid homology to M41(Table 1). Egypt/ F/03 showed 34 point mutations from H120; 20 silent and 14 non silent mutations. On the other hand, it showed 30 point mutations; 10 silent and 20 non silent mutations from M41 (Fig. 3, 4). Sixteen potential glycosylation sites were found in Egypt/F/03 while 17 were found in H120 and M41 (Fig. 4). All potential glycosylation sites found in Egypt/F/03 were shared with those found in H120 and M41(Fig. 4).

\section{Virulence test}

Chickens inoculated with Egypt/F/03 exhibited snicking and rales in approximately $50 \%$ of infected birds at $3^{\text {rd }}$ day of inoculation. Conjunctivitis was observed in 20/30 at $3^{\text {rd }}$ day PI that was elevated to $22 / 30$ by the $5^{\text {th }}$ day PI of infected birds whereas no birds exhibited watery eyes. Six birds were dead after Egypt/F/03 experimental infection; 4 birds in the $7^{\text {th }}$ day PI and 2 birds in the $8^{\text {th }}$ day PI. Postmortem examination of dead birds, revealed petechial haemorrhages in larynx and thymus, severe congestion of liver, spleen and lungs as well as renal haemorrhages. These changes appeared but in milder form in birds sacrificed at 5 days PI. Histopathological examination of sacrificed birds at 5 days PI and freshly dead birds at 7 days PI revealed mucus, marked loss of cilia, desquamation, mononuclear infiltration, epithelial hyperplasia and vascular congestion of the trachea (Fig. 5). Kidneys showed severe changes including haemorrhages, degenerative changes in renal tubules and hypercellularity of the renal glomeruli as well as focal lymphocytic infiltration (Fig. 5). In general the tracheal and renal histopathological lesions were more severe in dead birds (Fig. 5b, d) than birds sacrificed at 5 days PI (Fig. 5a, c).

\section{Vaccination trial}

Chickens vaccinated with H120 (Group A) showed 58.3\% protection $(7 / 12)$ by virus reisolation procedure and $66.6 \%(8 / 12)$ protection by histopathology after challenge with Egypt $\backslash \mathrm{F} / 03$ while all control unvaccinated birds (Group B) were not protected (5/5) (Table 2). On day four PI, the kidneys of (3/12) birds in group A (vaccinated and challenged with IBV) showed focal lymphocytic infiltration, urates deposition and degenerative changes in renal tubules while birds of group B (unvaccinated and challenged with IBV) showed multifocal lymphocytic infiltration, urates deposition and degenerative changes in renal tubules in $4 / 5$ birds, while only focal lymphocytic infiltration, urates deposition and degenera- 
Table I: Nucleotide and amino acid identities of Egypt/F/03 with selected IBV sequences

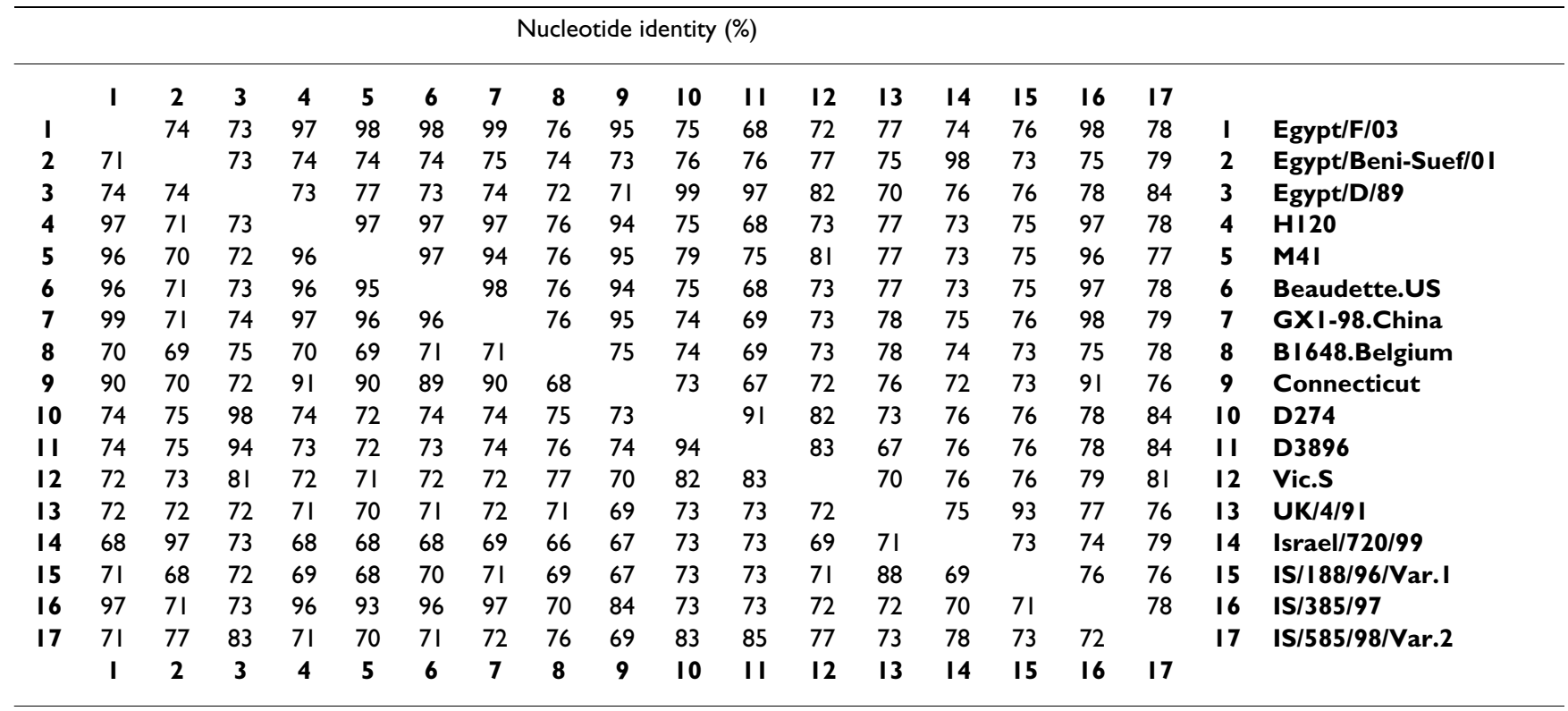

Amino acid identity (\%)

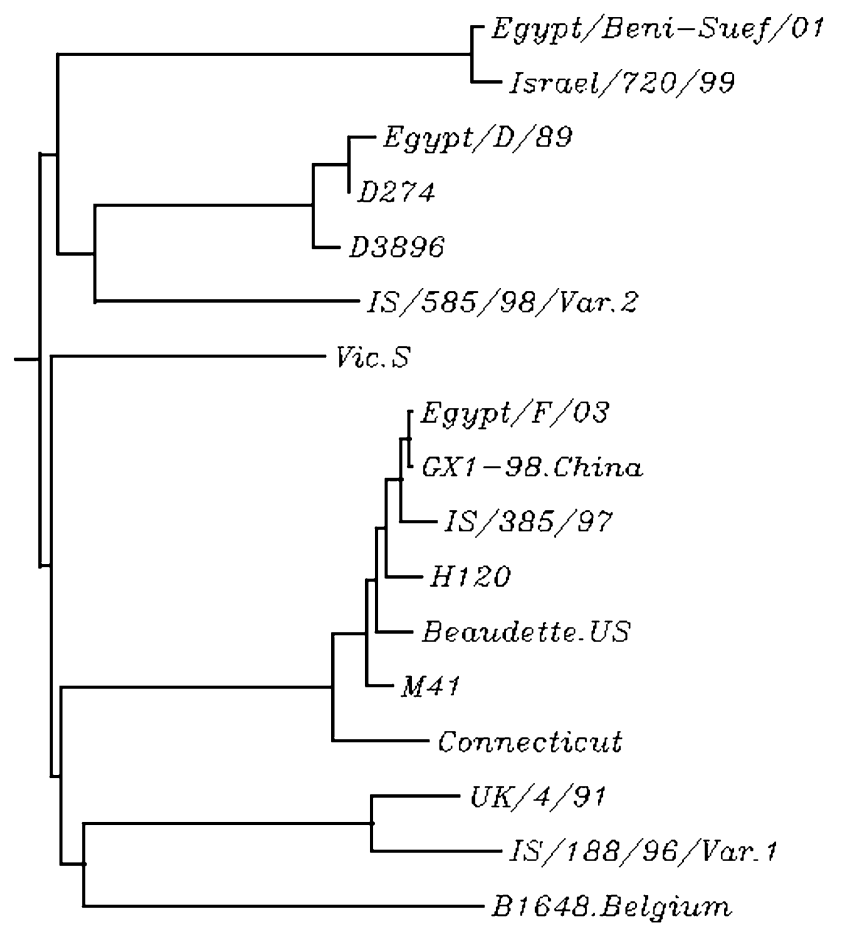

Figure 2

IBV SI gene sequence relationships expressed as a phylogenetic tree of Egypt/F/03 isolate and selected IBV reference strains. tive changes in renal tubules were observed in $1 / 5$ birds. Birds in group C (vaccinated unchallenged group) did not show any abnormalities $(0 / 12)$ either in tracheae or kidneys. Immunofluorescenct assay on kidneys of challenged and unchallenged groups showed that all challenged unvaccinated and 3/12 of challenged vaccinated groups possessed kidney immunofluorescence. None of control unchallenged groups possessed kidney immunofluorescence (Table 2).

\section{Discussion}

In this study, an Egyptian IBV strain; Egypt $\backslash \mathrm{F} / 03$ was isolated from a tissue pool of kidney and trachea from unvaccinated broiler flock with a history of respiratory and renal disease. The strain produced typical lesions of IBV in inoculated embryos and identified as IBV by Dot-ELISA and RT-PCR. The isolate was found to be devoid of major concomitant viruses; avian influenza virus, Newcastle disease virus, infectious laryngotracheitis virus, reovirus and adenovirus (data not shown).

S1 sequence analysis of Egypt/F/03 revealed its close relatedness to Mass serotype. It showed high nucleotide similarities to GX1-98.China (99\% nucleotide and amino acid identities), Beaudette-US (98\% nucleotide and 96\% amino acid identities), IS/385/97 (98\% nucleotide and $97 \%$ amino acid identities), H120 (97\% nucleotide and amino acid identities) and M41 (98\% nucleotide and 96\% amino acid identities). 


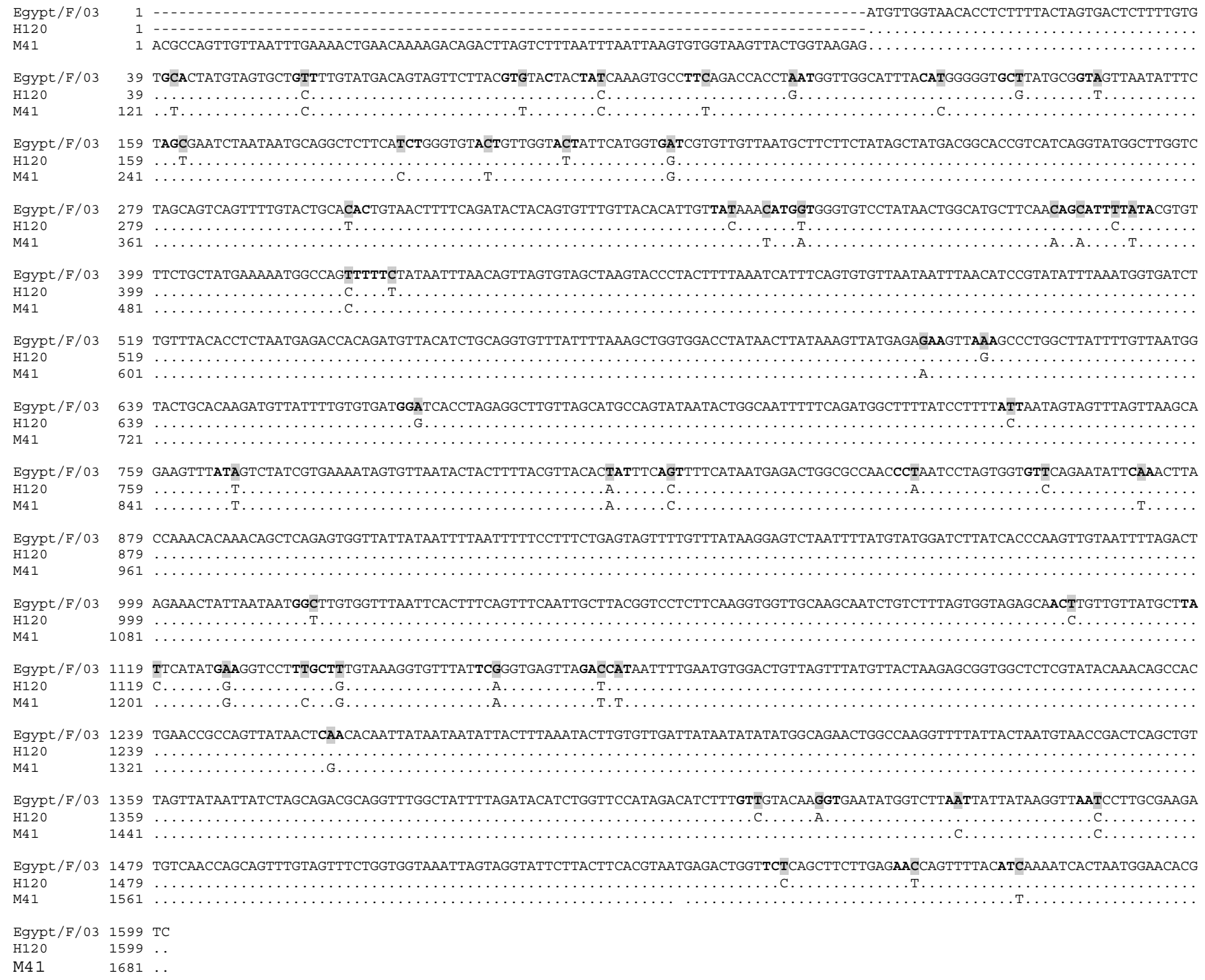

\section{Figure 3}

Nucleotides identities of Egypt/F/03 with commonly used vaccine strains sequences. Dots indicate residues identical to Egypt/F/03. Bold letters denotes codon areas. Shaded letters denote sites of differences.

It is known that the most severe clinical response of IBV appears in very young chickens and severity is alleviated in older chickens $[19,20]$. This fact explains the high mortality rate observed in 1-day-old chickens that experimentally inoculated with Egypt/F/03 compared to mortality pattern in the original flock (25-day-old chickens). The presence of acute interstitial nephritis on days 5 and 7 post infection indicated that Egypt $\mid \mathrm{F} \backslash 03$ is a nephrogenic IBV. The microscopic findings of the renal tubules matched the general findings recorded with nephrogenic IBV strains [21,22]. The microscopic findings in tracheal sections appeared similar to those recorded by $[19,21]$ including: loss of cilia, degenerative changes of the tracheal mucosa, irregular loss of epithelium, desquamation of the sloughed epithelium in the tracheal lumen and lymphocytic infiltration that ranged from focal aggregation to diffuse massive infiltration. Severe renal haemorrhages observed grossly and in hisopathological sections of birds dead after experimental infection with Egypt/F/03 denote that deaths resulted from acute renal failure. Our finding regarding the presence of petechial haemorrhages in larynx and thymus as well as severe congestion of liver, spleen and lungs in birds dead after IBV experimental infection is in agreement with $[23,24]$ who confirmed the presence of IBV viral antigens in such organs.

Evaluation of the immune response to IBV vaccination is based on several criteria including: clinical signs, tracheal 


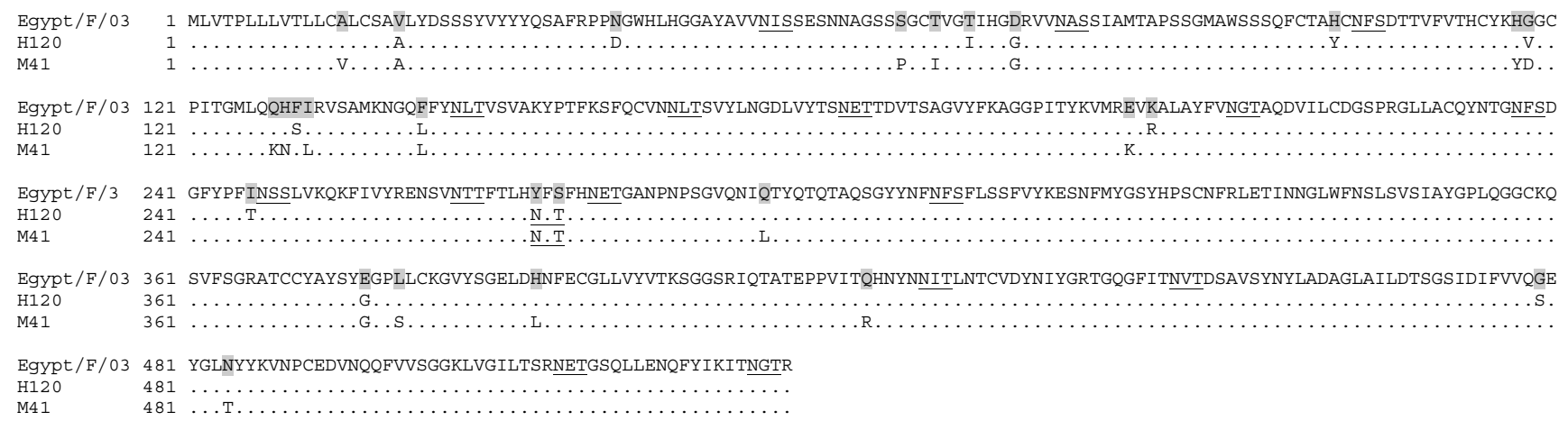

\section{Figure 4}

Amino acid identities of Egypt/F/03 with commonly used vaccine strains sequences. Dots indicate residues identical to Egypt/F/03. Potential glycosylation sites (NXS or NXT, except where $X=P$ ) are underlined. Shaded letters denote sites of differences. A:Alanine, C:Cysteine, D:Aspartic acid, E:Glutamic acid F:Pheny-lalanine, G:Glycine, H:Histidine, I:Isoleucine, K:Lysine, L:Leucine, M:Methionine, N:Asparagine, P:Proline, Q:Glutamine, R:Arginine, S:Serine, T:Threonine, V:Valine, W:Tryptophan, Y:tyrosine.

histological lesion, virus neutralization, virus re-isolation from trachea, antigen detection in trachea and/or kidney by immunofluorescent or immunoperoxidase techniques [25-29]. In this study we used tracheal histological lesion and virus re-isolation as parameters for tracheal protection. Kidney histopathology and antigen detection by IFA were used as indicators of kidney protection. Complete protection is expected upon using closely related vaccine strain as the degree of cross protection among IBV strains generally reflects the similarities between the $S$ proteins $[12,30]$. The re-isolation of Egypt/F/03 from the trachea of vaccinated birds and the presence of tracheal and renal microscopic lesions as well as viral antigen in kidneys (by IFA) in H120 vaccinated birds denote lack of complete protection afforded by $\mathrm{H} 120$ vaccination.

H120 is a mild vaccine and it is possible that the challenge virus was too virulent for the level of immunity that the vaccine produced in these young chickens. Other possible consideration includes that baby chickens are not fully immunocompetent at one-day of age, the time that they were vaccinated for the protection study experiment. However, commercial broiler chickens possess maternally derived antibodies, are routinely vaccinated at one-day of age $[31,32]$ without apparent interference by the maternal derived antibodies in the development of active immunity, at least in the respiratory tract that measured by challenge [33]. On the other hand, variable results were recorded regarding homologous protection of IBV. Cavanagh et al. [12] inoculated groups of 10 chickens with the virulent $\mathrm{UK} / 6 / 82$ isolate and challenged with isolates that differed by up to $4 \%$ of $S 1$ amino acids. Challenge with two variants (98\% S1 identity with $\mathrm{UK} / 6 / 82)$ resulted in challenge scores virtually the same as with the homologous challenge however, challenge with two others iso- lates (96\% and $98 \%$ S1 identity, respectively), resulted in less cross-protection, although the numbers were not statistically significantly different.

In the $S 1$ subunit, three HVRs are located within amino acids 38-67, 91-141 and 274-387 [4-6]. HVR1 and HVR2 contain sequences that have been associated with specific IBV serotypes $[34,35]$ as well as serotype specific neutralizing epitopes $[4,5,14]$. IBV serotypes commonly differ by 20 to $25 \%$ in S1 [11,36] but some serotypes differ in S1 by as little as 2\% [13]. Although H120 showed 97\% amino acid and nucleotide identity to Egypt/F/03, it possesses 34 different nucleotides that resulted in 14 amino acid substitutions. Among such amino acids, one is located in HVR1, four in HVR2 and one in HVR3 (Fig.4). The region between amino acid residues 123-152 has been previously identified as a possible region involved in the differing pathogenicity of Gray and non-virulent JMK strains [37]. Egypt/F/03 possesses different amino acid; phenylalanine within this region at positions 130 and 141 instead of serine and leucine in H120 respectively. It is apt to mention that some serotypes differ in S1 by as little as 10 amino acids [13], suggesting that only a few epitopes may induce most of the VN antibody [38].

\section{Conclusion}

Egypt/F/03 is a nephropathogenic IBV strain closely related to Mass serotype. Vaccination by $\mathrm{H} 120$ did not provide satisfactory protection against challenge with Egypt/F/03. Complete protection of trachea against the Egypt/F/03 and consequently efficient prevention of kidney infection may be quite feasible upon development of safe attenuated vaccines based on indigenous field strain. Preparation of live and inactivated vaccines from indigenous isolates should parallel periodic evaluation of cross- 


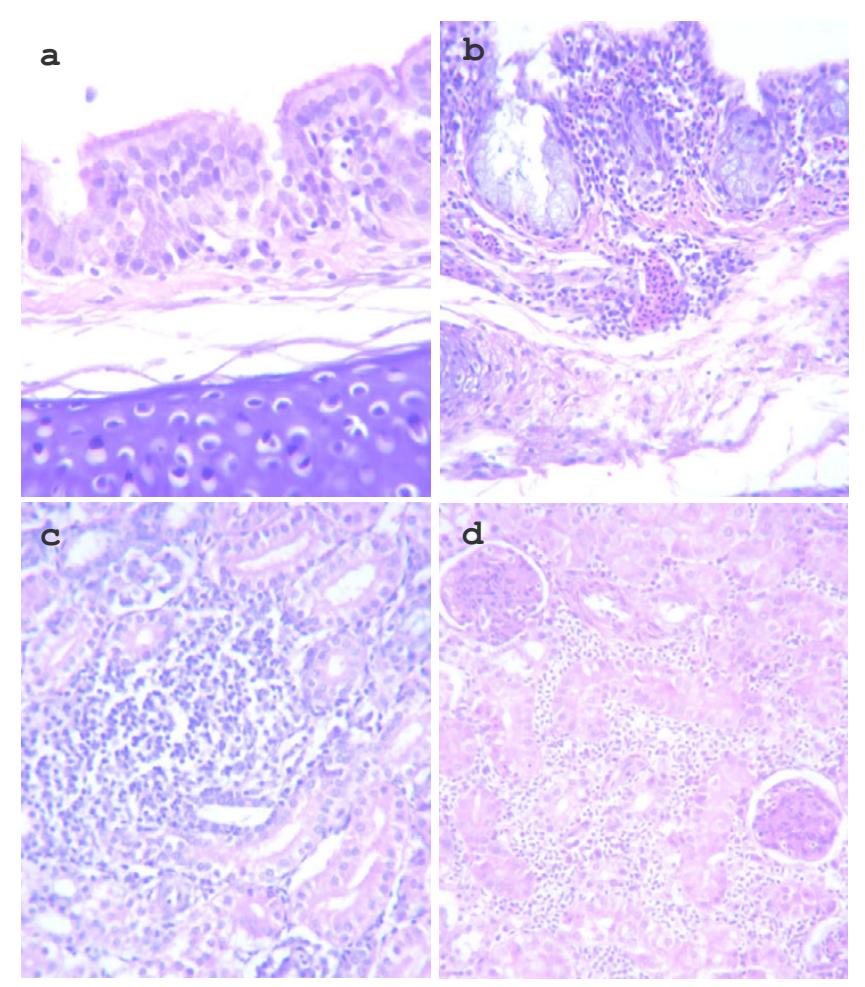

Figure 5

Trachea and kidney histopathology following experimental infection of I-day old chickens with Egypt/F/ 03. Trachea and kidney stained with $\mathrm{H}$ \& E: a. Trachea of chickens $5 \mathrm{~d}$ P.I with Egypt/F/03 showed hyperplasia, lymphcytic infiltration and oedema $(40 \times)$. b. Trachea of chickens 7 d P.I with Egypt/F/03 showed diffuse lymphocytic aggregation, degeneration of the epithelium mucus, and haemorrhages (20 $x)$. c. Kidney of chickens $5 \mathrm{~d}$ P.I with Egypt/F/03 showed focal lymphocytic aggregation in the interstitium and in the glomeruli, as well as degenerative changes in tubular epithelium $(40 \times)$. d. Kidney of chickens 7 d P.I with Egypt/F/03 showed massive renal haemorrhages and degeneration renal tubular epithelium $(20 \times)$.

protective capabilities of such vaccine(s) versus recently recovered field isolates in order to ensure optimum control of IBV.

\section{Methods}

\section{Embryonated chicken eggs}

SPF ECE obtained from Nile SPF (Koom Oshiem, Fayoum, Egypt) were used for isolation of the field isolate, serial passages, titration of the seed stocks of Egypt/F/03 and vaccine strain (H120), as well as virus re-isolation attempts following challenge in the protection study.

\section{Chickens}

Sixty nine commercial 1-day-old chickens (El-Waddi Co, Egypt) were reared under strict hygienic conditions in sep- arate rooms and used in both virulence test and protection study.

\section{Rabbit anti-IBV}

Rabbit anti-IBV polyclonal antiserum raised against vero adapted H120 vaccine was prepared previously in our lab [17] and used for detection of IBV antigens in both DotELISA and indirect immunofluorescent antibody technique.

\section{Clinical history}

Infectious bronchitis was diagnosed during Augest 2003 in Fayoum Governorate, Egypt. The outbreak occurred in 25-day-old commercial broiler farm with no previous IBV vaccination. The flock was vaccinated against Newcastle disease and infectious bursal disease viruses at 14 and 18 days of age respectively. The total flock density was 3000 birds. The first signs were depression and respiratory distresses including sneezing, coughing and rales. Other signs included conjunctivitis and watery eyes. Within a period of 10 days after the appearance of the disease, the mortality rate increased to $10 \%$ of the flock density. Postmortem examination of dead birds revealed increased tracheal mucus, severe renal congestion, urates filled ureters as well as congestion in liver and spleen.

\section{Virus isolation and passage in SPF ECE}

Egypt/F/03 was isolated from 25-day-old broiler chickens suffering from both respiratory and renal distresses from Fayoum Governorate in 2003. A kidney homogenate (10\% in sterile PBS) and a tracheal scraping suspension were pooled, centrifuged at $500 \times \mathrm{g}$ for $10 \mathrm{~min}$. The supernatant fluid was inoculated into chorioallantoic sac of 10day-old SPF ECE. Allantoic fluid was harvested after $48 \mathrm{~h}$ and was used for re-passage into ECE. Five eggs of the $4^{\text {th }}$ egg passage were incubated till being 18-day-old and examined for typical lesions of IBV (stunting, curling and urates deposition in ureters).

\section{Dot-ELISA for virus identification}

A Dot-ELISA was performed according to [39]. Briefly, NCM of convenient size was cut, marked with waterproof ink for identification and then soaked for $10 \mathrm{~min}$. in distilled water. NCM was laid on absorbent paper and airdried for $5 \mathrm{~min}$. Three $\mu \mathrm{l}$ of CAM homogenate of the $4^{\text {th }}$ virus passage of Egypt/F/03, positive control (CAM homogenate $48 \mathrm{~h}$ after inoculation of H120 vaccine) and negative control (normal CAM homogenate) samples were applied as small spots on the membrane. The dotted membrane was allowed to air dry for 15 min then blocked for $30 \mathrm{~min}$. in Tris buffer $(20 \mathrm{mM}$ Tris base, $500 \mathrm{mM} \mathrm{NaCl}$ $\mathrm{pH} 7.5$ ) containing $0.5 \%$ Tween 20 then rinsed for $5 \mathrm{~min}$. in Tris buffer. NCM was then incubated for $1 \mathrm{~h}$ with rabbit anti-IBV (prepared previously in our lab.) predilluted to 1:10 with diluents buffer (Tris buffer containing 0.05\% 
Table 2: Protection of chickens following vaccination with IBV HI 20 strain and challenged with Egypt/F/03

\begin{tabular}{|c|c|c|c|c|c|c|c|c|c|c|c|c|c|c|}
\hline \multirow{3}{*}{ Group $^{A}$} & \multirow{3}{*}{$n^{B}$} & \multirow{3}{*}{$\begin{array}{l}\text { Vaccina } \\
\text { tion }\end{array}$} & \multirow{3}{*}{$\begin{array}{l}\text { Challen } \\
g^{C}\end{array}$} & \multicolumn{4}{|c|}{ Tracheal Protection } & \multicolumn{7}{|c|}{ Kidney Protection } \\
\hline & & & & \multicolumn{2}{|c|}{ Virus Reisolation $^{D}$} & \multicolumn{2}{|c|}{$\begin{array}{c}\text { Tracheal } \\
\text { HistopathologyE }\end{array}$} & \multicolumn{4}{|c|}{ Kidney histopathology } & \multicolumn{3}{|c|}{ Immunoflourscence } \\
\hline & & & & Positive & $\begin{array}{c}\text { Negativ } \\
\mathrm{e}\end{array}$ & Positive & $\begin{array}{c}\text { Negati } \\
\text { ve }\end{array}$ & Normal & Focal & Multifocal & Diffuse & Positive & Negative & Intensity ${ }^{F}$ \\
\hline A & 12 & + & + & 5 & 7 & 4 & 8 & 9 & 3 & 0 & 0 & 3 & 9 & + \\
\hline B & 5 & - & + & 5 & 0 & 5 & 0 & 0 & 3 & 4 & 0 & 5 & 0 & +++ \\
\hline C & 12 & + & - & 0 & 12 & 0 & 12 & 12 & 0 & 0 & 0 & 0 & 12 & - \\
\hline
\end{tabular}

A Groups A and C were vaccinated by IBV HI20 vaccine at I-day of age while birds in group B were kept as unvaccinated control.

BNumber of birds used per group.

$C$ Four weeks post vaccination; chickens in group $A$ and $B$ were challenged by eye drop with $10^{5}$ EID 50 per bird of Egypt/F/03 while birds in group $C$ were not challenged and kept as vaccinated unchallenged control:(-) denotes unchallenged, while $(+)$ denotes challenged groups.

D Virus reisolation 4 days post challenge with Egypt/F/03 in SPF ECE. Unprotected tracheal samples showed positive IBV reisolation while protected tracheal samples showed negative results.

ETracheal histopathology 4 days post challenge with Egypt/F/03 was measured as tracheal histopathological scores. Tracheal samples showed high tracheal histopathological scores (score range: 6-8) were considered positive (unprotected). Negative (protected) tracheal scores range was I-2.

F Intensity of IFA: $(+)$ denotes few cells showed positive IFA reaction, (++) many cells showed IFA reaction, (+++) diffuse IFA reaction.

Tween20). Bound antibodies were detected by incubating NCM for $1 \mathrm{~h}$ with goat anti-rabbit peroxidase conjugate (Sigma, Co.) prediluted to 1:500 with diluent buffer. NCM was rinsed three times $(10 \mathrm{~min}$. each) with Tris buffer after each step. Finally the membrane was incubated for $15 \mathrm{~min}$. in $60 \mathrm{~mm}$ Petri dish containing $20 \mathrm{ml}$ 4-chloro-1-naphthol and hydrogen peroxide substrate working solution. The membrane was rinsed with water to stop the enzymatic reaction. Blue dots denote positive reaction.

\section{Viral inactivation, polymerase chain reaction and SI gene cycle sequencing}

Egypt/F/03 was inactivated by treating $2 \mathrm{ml}$ of the infective allantoic fluids with an equal volume of molecular biology grade phenol ( $\mathrm{pH} 4.3$ ) (Fisher Scientific, Fair Lawn, NJ). Following inactivation, the isolate was shipped to the University of Delaware as stipulated by an USDA Veterinary Import Permit issued to J. Gelb, Jr. The phenoltreated allantoic fluid was vortexed and then centrifuged at $12,000 \times \mathrm{g}$ for $3 \mathrm{~min}$. The supernatant was harvested and an additional treatment using phenol/chloroform/ isoamyl alcohol ( $\mathrm{pH}$ 4.3) (Fisher Scientific) was performed. Viral RNA was harvested from the aqueous layer and extracted using a Qiagen Viral RNA Mini Kit (Qiagen, Inc., Valencia, CA). The RNA was eluted in sterile diethyl pyrocarbonate (DEPC)-treated water and stored at $-70^{\circ} \mathrm{C}$. RT was performed on the viral RNA using the GeneAmp RNA PCR Core Kit (Applied Biosystems, Foster City, CA). Approximately $2 \mu \mathrm{l}$ of the extracted viral RNA was used to synthesize cDNA. Amplification of the S1 gene was performed using S1OLIGO3' (5'-CATAACTAACATAAGGGCAA-3') and S1OLIGO5' (5'TGAAACTGAACAAAAGAC-3') primers [10,37]. PCR of S1 gene was performed as described [11] with the exception that extension was performed at $60^{\circ} \mathrm{C}$.

S1 PCR product was cut from $1.8 \%$ agarose gels, purified with the QIAquick gel extraction kit (Qiagen, Inc.) and the DNA was quantitated as described [11]. Purified RT-PCR product was sequenced in the forward and reverse directions using the same primers. Sequencing was performed as described [11].

\section{Sequence analysis}

A BLAST $^{\circledast}$ analysis [40] was initially performed using the S1 sequence of Egypt/F/03 (DQ487085) to establish its identity to GenBank accessions. A comparative analysis of S1 sequences was performed using the CLUSTAL W Multiple Sequence Alignment Program, version 1.83 [41]. The tree was constructed using the neighbour-joining program [41]. IBV S1 sequences representative to genotypes used for the alignments were obtained from the GenBank and EMBL database. They include: Egypt/Beni-Suef/01 ( $\underline{\text { AF395531) }}$, Egypt/D/89 (DQ487086) H120( M41(M21883), Beaudette.US (ㅍ311362), GX198.China(AY319302), Connecticut(L18990), B1648.Belgium (X87238), D274 (X15832), D3896 (ㅍ2084), Vic.S $(\underline{\mathrm{U} 29519}), \quad \mathrm{UK} / 4 / 91(\underline{\mathrm{AF} 093794}), \quad \underline{\mathrm{Xsrael} / 720 /}$

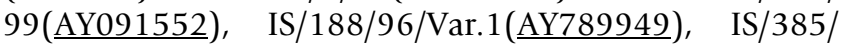
97( $\underline{\text { AY789957) }}$ and IS/585/98/Var.2 (AY789962). Egypt/ F/03 was compared with $\mathrm{H} 120$ and M41 vaccine sequences using multisequence alignment [42] and sequences were presented using BOXSHADE 3.21 [43].

\section{Virulence test}

Forty 1-day-old chickens were used. Thirty chickens were infected by intraocular instillation of $10^{5} \mathrm{EID}_{50} / 100 \mu \mathrm{l}$ of 
Egypt/F/03 according to [21] while other birds were kept as control uninfected group. Clinical signs and gross postmortem lesions as well as mortalities were recorded. Microscopic examinations of both tracheae and kidneys were performed at 5 and 7 days post infection.

\section{Protection study}

Twenty nine commercial 1-day-old chickens were used to evaluate the protection provided by $\mathrm{H} 120$ vaccination against challenge with Egypt/F/03. Birds were divided into three groups; A $(\mathrm{n}=12), \mathrm{B}(\mathrm{n}=5), \mathrm{C}(\mathrm{n}=12)$. Vaccination was performed at day 1 by eye drop application. Single dose of H120 vaccine (Nobilis, Intervet, The Netherlands $\mathrm{BV}$ ) was used for each bird in groups $\mathrm{A}$ and $\mathrm{C}$ according to manufacturer's instructions while birds in group B were kept as unvaccinated control. Four weeks post vaccination, chickens in group A and B were challenged by eye drop with Egypt/F/03 (10 EID $_{50}$ per bird) while birds in group $\mathrm{C}$ were not challenged and kept as vaccinated unchallenged control. Tracheae of all birds from all groups were collected four days post challenge for virus reisolation attempts and histopathological examination. Tracheal scrapings were emulsified in $2 \mathrm{ml}$ of sterile PBS and centrifuged at $500 \times \mathrm{g}$ for $3 \mathrm{~min}$. Virus reisolation attempts were performed by inoculating 2-3, 10-day-old SPF ECE by the supernatant fluid of each sample as described [44]. Embryos were examined for typical lesions of IBV. For histopathological examination, tracheae were fixed in formalin, processed routinely for histopathology and stained with haematoxylin and eosin. The trachea from each bird was examined microscopically and assigned lesion scores of $0-3$ with $0=$ none, $1=$ focal, $2=$ multifocal, 3 = diffuse. Tracheae were scored for the amount of mucous, loss of cilia, epithelial hyperplasia, necrosis, lymphocyte and heterophil infiltrations as well as the extent of tissue reaction. The scores for each bird were added and the mean score for the birds in each group was calculated [45]. Kidney samples were also taken 4 days post challenge and examined microscopically for tubular degeneration and inflammation consistent with interstitial nephritis. Focal, multifocal and diffuse were used to assign kidney histopathology. The presence of viral antigens in kidneys was screened by immunofluorescent antibody technique.

\section{Indirect immunofluorescent antibody technique (IFA)}

It was performed according to [46] to detect viral antigens in the kidneys of birds after challenge with Egypt/F/03 in protection study. Briefly, deparaffinized slides were incubated with rabbit anti-IBV antibodies (1:5) for $1 \mathrm{~h}$ and subsequently with FITC-conjugated goat anti-rabbit antibody (Kirkegaard and Perry Laboratories, Gaithersburg, Md.) (1:1000) for $1 \mathrm{~h}$. Both primary and secondary antibodies were diluted in PBS. Slides were rinsed three times (10min./single wash) with PBS after each step. Slides were then mounted using glycerol/PBS (without allowing the slides to dry) and examined under fluorescent microscopy.

\section{Abbreviations}

CAM, chorioallantoic membrane; ECE, Embryonated chicken eggs; EID, egg infective dose fifty; FITC, fluorescien isothiocynate; HVR, hypervariable region; IBV, infectious bronchitis virus; NCM, nitrocellulose membrane; PBS, phosphate buffer saline; RT, reverse transcriptase; SPF, specific-pathogen-free.

\section{Competing interests}

The author(s) declare that they have no competing interests.

\section{Authors' contributions}

ASA isolated and serologically characterized Egypt/F/03 virus and performed virulence test as well as protection study. He also performed multisequence alignment, phylogenetic analysis and drafted the manuscript, MFE provided sample for isolation, helped in performing virulence test and protection study and reviewed the manuscript, JGJr helped in performing RT-PCR, S1 gene sequence of Egypt/F/03 and critically reviewed the manuscript, BSL made RT-PCR and S1 gene sequence of Egypt/ F/03.

\section{References}

I. Cavanagh D, Naqi S: Infectious bronchitis. In Diseases of Poultry IIth edition. Edited by: Saif YM, Barnes HJ, Glisson JR, Fadly AM, McDougald LR, Swayne DE. Ames: lowa State University Press; 2003:101-119.

2. Mayo MA, Pringle CR: Virus Taxonomy 1997. J Gen Virol 1998, 79:649-657

3. Cavanagh D: Coronaviruses in poultry and other birds. Avian Pathol 2005, 34:439-448.

4. Cavanagh D, Davis PJ, Mockett APA: Amino acids within hypervariable region I of avian coronavirus IBV (Massachusetts serotype) spike glycoprotein are associated with neutralization epitopes. Virus Res 1988, I I:141-150.

5. Koch G, Hartog L, Kant A, van Roozelaar DJ: Antigenic domains on the peplomer protein of avian infectious bronchitis virus: correlation with biological functions. J Gen Virol 1990, 71:1929-1935.

6. Moore KM, Jackwood MW, Hilt DA: Identification of amino acids involved in a serotype and neutralization specific epitope within the SI subunit of avian infectious bronchitis virus. Arch Virol 1997, 142:2249-2256.

7. Jia W, Wang X, Parrish CR, Naqi SA: Analysis of the serotypespecific epitopes of avian infectious bronchitis virus strains Ark99 and Mass4 I. J Virol 1996, 70:7255-7259.

8. Niesters H, Bleumink PN, Osterhaus A, Horzinek MC, van der Zeijst BAM: Epitopes on the peplomer protein of infectious bronchitis coronavirus strain M4I as defined by monoclonal antibodies. Virology 1989, 161:5II-519.

9. Lin Z, Kato A, Kudou $Y$, Ueda S: A new typing method for the avian infectious bronchitis virus using polymerase chain reaction and restriction enzyme fragment length polymorphism. Arch Virol 1991, I 16:19-3I.

10. Kwon HM, Jackwood MW, Gelb J Jr: Differentiation of infectious bronchitis virus serotypes using the polymerase chain reaction and restriction fragment length polymorphism analysis. Avian Dis 1993, 37:194-202. 
11. Kingham BF, Keeler CL, Nix WA, Ladman BS, Gelb J Jr: Identification of avian infectious bronchitis virus by direct automated cycle sequencing of the S-I gene. Avian Dis 2000, 44:325-335.

12. Cavanagh D, Ellis MM, Cook JKA: Relationship between sequence variation in the $S I$ spike protein of infectious bronchitis virus and the extent of cross-protection in vivo. Avian Pathol 1997, 26:63-74.

13. Cavanagh D, Davis PJ, Cook JKA, Li D, Kant A, Koch G: Location of the amino-acid differences in the $S I$ spike glycoprotein subunit of closely related serotypes of infectious bronchitis virus. Avian Pathol 1992, 21:33-43.

14. Kant A, Koch G, van Roozelaar DJ, Kusters JG, Poelwijk FAJ, van der Zeijst BAM: Location of antigenic sites defined by neutralizing monoclonal antibodies on the $S \mathbf{I}$ avian infectious bronchitis virus glycopolypeptide. J Gen Virol 1992, 73:591-596.

15. Sheble A, Sabry MZ, Davelaar FG, Burger AG, Khafagy AK, Moustafa F, Moustafa MM, Henna M: Present status of infectious bronchitis in Egypt. J Egyp Vet Med Assoc 1986, 4:393-4II.

16. El-Kady MF: Studies on the epidemiology and means of control ofinfectious bronchitis disease in chickens in Egypt. In $\mathrm{PhD}$ thesis Faculty of Veterinary Medicine, Cairo University, Egypt: 1989.

17. Abdel-Moneim AS, Madbouly HM, Gelb J Jr, Ladman BS: Isolation and identification of Egypt/Beni-Suef/OI a novel genotype of infectious bronchitis virus. Vet Med J Giza, Egypt 2002, 50:1065-1078.

18. Sultan HA, Tantawi L, Youseif Al, Ahmed AAS: Urolithiathis in white commercial egg laying chickens associated with an infectious bronchitis virus. 6th Sci Conf Egyp Vet Poult Assoc 2004:155-169.

19. Toro H, Kaleta EF, Herbst W, Peixoto P, Frese K: Differences inpathogenicity for young chickens among field isolates of infectious bronchitis virus. Arch Med Vet Chole 1988, 20:44-50.

20. Mohamed BT: Studies on the prevalence and epidemiology of infectious bronchitis in broiler chickens in El-Minia Governorate. In Master thesis Cairo University, Beni-Suef branch, Egypt; 2005.

21. Purcell DA, Tham VL, Surman PG: The histopathology of infectious bronchitis in fowls infected with a nephrotropic $T$ strain of virus. Aus Vet J 1976, 52:85-9I.

22. Albassam MA, Winterfield RW, Thacker HL: Comparison of the nephropathogenicity of four strains of infectious bronchitis virus. Avian Dis 1986, 30:468-476.

23. Cumming RB: The control of avian infectious bronchitis/nephrosis in Australia. Aust Vet $J$ 1969, 45:200-203.

24. Abdel-Moneim AS, Madbouly HM, El-Kady MF: In vitro characterization and pathogenesis of Egypt/Beni-Suef/0I; a novel genotype of infectious bronchitis virus. Beni-Suef Vet Med J Egypt 2005, I 5(2): 127-133.

25. Winterfield RW, Fadly AM: Criteria for examining the immune response to infectious bronchitis virus. Avian Dis 1971, 15:56-67.

26. Winterfield RW, Fadly AM: Some characteristics of isolates of infectious bronchitis virus from commercial vaccines. Avian Dis 1972, 16:746-755.

27. Winterfield RW, Fadly AM, Bickford AA: The immune response to infectious bronchitis virus determined by respiratory signs, virus infection, and histopathological lesions. Avian Dis 1972, 16:260-269.

28. Lambrechts $C$, Pensaert M, Ducatelle R: Challenge experiments to evaluate cross-protection induced at the trachea and kidney level by vaccine strains and Belgian nephropathogenic isolates of avian infectious bronchitis virus. Avian Pathol 1993, 22:577-590.

29. Ladman BS, Pope CR, Ziegler AF, Swieczkowski T, Callahan JM, Gelb $\mathrm{J} J \mathrm{r}$ : Protection of chickens following live and inactivated virus vaccination against challenge with nephropathogenic infectious bronchitis virus PA/Wolgemuth/98. Avian Dis 2002, 46:938-944

30. Cavanagh D: Severe acute respiratory syndrome vaccine development: experiences of vaccination against avian infectious bronchitis coronavirus. Avian Pathol 2003, 32:567-582.

31. Andrade LF, Villegas P, Fletcher OJ: Vaccination of day-old broilers against infectious bronchitis: Effect of vaccine strain and route of administration. Avian Dis 1983, 27:178-187.

32. Davelaar FD, Kouwenhoven B: Vaccination of one day-old broilersagainst infectious bronchitis by eye drop application or coarse droplet spray and the effect of revaccination by spray. Avian Pathol 1983, 9:499-5I0.

33. Raggi LG, Lee GG: Lack of correlation between infectivity, serological response, and challenge results in immunization with an avian infectious bronchitis vaccine. J Immunol 1965, 94:538-543.

34. Binns MM, Boursnell ME, Tomley FM, Brown DK: Comparison of the spike precursor sequences of coronavirus IBV strains M4I and 6/82with that of IBV Beaudette. J Gen Virol I986, 67:2825-283I.

35. Kusters JG, Niesters HG, Lenstra JA, Horzinek MC, van der Zeijst $B A$ : Phylogeny of antigenic variants of avian coronavirus IBV. Virology 1989, 169(1):217-21.

36. Keeler CL, Reed KL, Nix WA, Gelb J Jr: Serotype identification of avian infectious bronchitis virus by RT-PCR of the peplomer (S-I) gene. Avian Dis 1998, 42:275-284.

37. Kwon HM, Jackwood MW: Molecular cloning and sequence comparisonof the SI glycoprotein of the Gray and JMK strains of avian infectious bronchitis virus. Virus Genes 1995, 9:219-229.

38. Hodgson T, Casai R, Dove B, Britton P, Cavanagh D: Recombinant infectious bronchitis coronavirus Beaudette with the spike protein gene of the pathogenic M4I strain remains attenuated but induces protective immunity. J Virol 2004, 78:|3804-| 38|| .

39. Hawkes R, Niday E, Gordan J: A dot-immunobinding assay for monoclonal and other antibodies. Anal Bioch 1982, I I 9: I 42-I47.

40. Altschul SF, Gish W, Miller W, Myers EW, Lipman DJ: Basic local alignment search tool. J Mol Biol 1990, 15:403-410.

4l. GenomeNet [http://www.genome.jp/]

42. BCM search launcher: Multiple Sequence Alignments [http:/ /searchlauncher.bcm.tmc.edu/multi-align/multi-align.html]

43. BOXSHADE 3.21 [http://www.ch.embnet.org/software/ BOX form.html]

44. Gelb J Jr, Killian SL: Serum antibody responses of chickens following sequential inoculation with different infectious bronchitis virus serotypes. Avian Dis 1987, 31:5 I3-522.

45. Andrade LF, Villegas P, Fletcher OJ, Laudencia R: Evaluation of ciliary movement in tracheal rings to assess immunity against infectious bronchitis virus. Avian Dis 1982, 26:805-8I5.

46. Grist NR, Bell EJ, Follett EAC, Urquhart GED: Diagnosticmethods in clinical virology 3rd edition. Blackwell Scientific I33 (I5) 2. Publications, Osney Mead, Oxford, OX2 OEL; 1979:3 I-43.
Publish with BioMed Central and every scientist can read your work free of charge

"BioMed Central will be the most significant development for disseminating the results of biomedical research in our lifetime. "

Sir Paul Nurse, Cancer Research UK

Your research papers will be:

- available free of charge to the entire biomedical community

- peer reviewed and published immediately upon acceptance

- cited in PubMed and archived on PubMed Central

- yours - you keep the copyright
BioMedcentral 